\title{
Analysis of Heavy Metals Concentration in Landfill Soil
}

\author{
Er. Gurbaksh Singh \\ Department of Civil Engineering \\ Indo global group of colleges \\ Abhipur, Mohali, Punjab, India,
}

\author{
Er. Ritu Goyal \\ Department of Civil Engineering \\ Indo global group of colleges \\ Abhipur, Mohali, Punjab, India,
}

\begin{abstract}
Our Environment is the base of life we are living in. Unfortunately, with the advancement in technology and development, natural resources are getting depleted day by day. Non-renewable resources are used without consideration of their importance for us. Over consumption of resources leading in generation of different types of wastes. Landfills are increasing day by day, even localities getting affected with household wastes because of improper management. Land degradation, water contamination and poor air quality are the possible factors produced through wastes. Leachate generation under mixed wet waste is polluting our groundwater while contaminating the soil as well. Toxic gas is also harming the surrounding atmosphere. Municipal solid waste consists of dry waste, wet waste, e-waste and construction and demolition waste. Toxicity resulted from organic pollutants and inorganic pollutants are contaminating the top soil as well as subsurface soil. Measurement of toxic metals can be done on the basis of qualitative as well as quantitative level. Method used for testing the presence of toxic metals in soil is based on spectrophotometer and chromatography. Chemical analysis of soil can be done using Atomic Absorption Spectrophotometer (AAS) and Inductively Coupled Plasma Mass Spectrometry(ICP-MS). In this study organic pollutants presence in landfill soil of Dadu Majra were examined using AAS. Furthermore, its effect on soil fertility was examined upto depth of $60 \mathrm{~cm}$. It was examined that the presence of Manganese(Mn) in the Dadu Majra landfill soil has increased.
\end{abstract}

Keywords:- Topsoil and subsoil, Micronutrients, Landfill, Waste.

\section{INTRODUCTION}

Landfill waste consists of different kinds of waste generated from industries, household, demolished sites, factories and electronic. All of the waste contains metals whose excessiveness can lead to threats for human health. Toxic metals are kind of metals which demands special treatment as these metals cannot be separated easily from the host sites. Leachate generated from non-engineered landfill site percolates into the sub-soil and can contaminate the groundwater. So, non-engineered landfills are the major cause of contamination of groundwater[1]. It also affects the micro and macronutrients present in soil for example phosphorus, magnesium, manganese, iron and copper. The landfill of Dadu Majra site is situated in Chandigarh with area of 45.11 acres. This landfill is located in sector 38 of Chandigarh city and open to the environment causing air pollution as well as soil pollution[2].The percolation of leachate from municipal solid waste landfill is continuous process. In fact, during the rainy season the leachate can get mixed in the nearby rivers. So, it is necessary to manage the waste at landfill with proper techniques.

Landfill consists of both hazardous and non-hazardous waste disposed openly on surface. Further, Soil-waste interaction results in the formation of toxic compounds. Each waste is enriched with different toxic elements. It is predicted that approximately 100 Million tonnes/day waste would be generated in 2021 with a gradual increase in future[3]. E-waste is also increasing day by day, nearly 300 million tons of e-waste is produced yearly. India is the 5th major producer of e-waste [4]. E-waste consists of lots of heavy metals and hazardous metals. From e-waste generated, some is recycled through pyrolysis and incineration and non-recyclable e-waste is dumped over landfill.

From the different wastes the soil properties get affected and the toxicity occurs. Total waste generated in Chandigarh was 167362 tonnes in the year 2018 as data provided by Chandigarh Pollution Control Committee: 2018-2019.Only 33 percent of waste was processed which means the dump is increasing in comparison to last record. In this study, soil samples were tested using Atomic absorption spectrophotometer for different elements like copper, Zinc, Ferrous, Manganese and the $\mathrm{pH}$ value as well as water holding capacity of samples was calculated.

\section{SAMPLES AND TESTING}

\section{A. $\quad$ Sampling}

After the collection of samples, it was dried before sieving it through $2.36 \mathrm{~mm}$ sieve. As shown in the figures, samples were stored in the porcelain dishes. Before storing samples into dishes, it was cleaned properly and oven dried at $103^{\circ}$ to $105^{\circ}$ so that no moisture is available in it. Now, aqua regia was prepared with 1:3 proportions of Nitric acid and Hydrochloric acid. Soil sample of $5 \mathrm{~g}$ was weighed from each sample and it was digested with prepared aqua regia with ratio 1:1.4. This digestion is acidic and the samples were placed in fume hood at a temperature of $60^{\circ}-70^{\circ}$ until we get a light colored and clear solution. Do not let samples dry during the digestion process. Now, wash down flask or beaker walls and watch glass cover with 

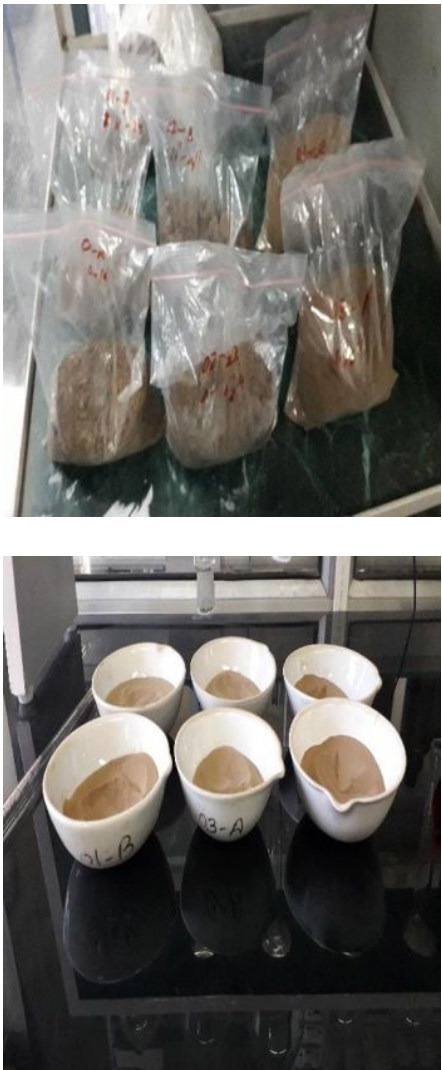

Figure 1: Samples taken and after basic preparation of drying and sieving.

metal free distilled water. Filter if necessary, using glass fiber filters. Transfer filtrate to a $100 \mathrm{ml}$ volumetric flask with two portions of distilled water. Take portions of this solution for required metal determinations. Volume of samples can be prepared on the basis of information provided in "table 1 ".

Table:1. Acids volume required for expected metals conc.

\begin{tabular}{|l|l|}
\hline Estimated metal conc.(mg/l) & Sample volume required $(\mathbf{m l})$ \\
\hline Less than 0.1 & 1000 \\
\hline $0.1-10$ & 100 \\
\hline $10-100$ & 10 \\
\hline
\end{tabular}

\section{B. $\quad$ Testing methods adopted}

Samples were treated using AAS(Atomic absorption spectrophotometer), in this method a sample is aspired into a flame and atomized. A light beam is directed through the flame into a monochromator and on to a detector that measures the amount of light absorbed by the atomized element in the flame. Because each metal has its own characteristic absorption, wavelength, a source lamp composed of that element is used. The amount of energy at the characteristic wavelength absorbed in the flame is proportional to the concentration of the element in the sample over a limited concentration range. Wavelengths used were different for each heavy metal and also calibrated at different standards. Zinc was assessed at a wavelength of $214 \mathrm{~nm}$ and the device was calibrated using $1 \mathrm{ppm}, 2 \mathrm{ppm}$ and 3 ppm zinc solution. Copper was calibrated using 02 ppm, $0.4 \mathrm{ppm}$ and $0.6 \mathrm{ppm}$ copper solution at wavelength of
$316.50 \mathrm{~nm}$. Manganese was measured using $252.20 \mathrm{~nm}$ wavelength and calibrated at $0.4 \mathrm{ppm}, 0.8 \mathrm{ppm}$ and $1 \mathrm{ppm}$ manganese solution. Ferrous was analyzed at a wavelength of $252.80 \mathrm{~nm}$ and calibrated at $1 \mathrm{ppm}, 2 \mathrm{ppm}, 3 \mathrm{ppm}$. Soil $\mathrm{pH}$ was also examined during this study in order to check the soil properties and it was determined using microprocessor based $\mathrm{pH}$ metre. Soil samples of $10 \mathrm{~g}$ from prepared samples as shown in figure 1 were taken and mixed with double distilled water of $25 \mathrm{ml}$ quantity. After mixing soil and double distilled water, it was stirred using a magnetic stirrer until a proper mixed sample was obtained. Further, calibration of obtained solution was done using standard certified reference material of $\mathrm{pH} 6.85$. Furthermore, electrode was cleaned with distilled water and dip into samples one by one cleaned after each dip with distilled water. Values for each sample were noted down.

\section{RESULTS AND DISCUSSION}

After performing AAS for the different elements like Copper, Zinc, Manganese and Ferrous. Values obtained are shown in table 2 .

The values obtained at varying depths were nearly the same for particular sample. But, the values obtained for manganese were higher for the sample 1 which was taken at lesser distance from landfill in comparison to other 2 samples. Manganese concentration was increasing with depths. Soil $\mathrm{pH}$, which falls in the category of higher infiltration property is also task of danger. Leachate flowing out from landfill penetrating through soil and can contaminate the Chandigarh groundwater. With the increase in concentration of manganese as compared with the values obtained in 2017[5]. From the results obtained, it can be assessed that concentration of manganese is increased from past two years and also increase in $\mathrm{pH}$ value can be seen. On the basis of these results, it can be concluded that the chances of soil contamination as well as groundwater contamination are more at present and it would increase in future, if landfill will not be managed wisely.

Table 2: Mean value of $\mathrm{pH}$ and concentration of different heavy metals (in

\begin{tabular}{|l|c|c|c|c|c|}
\hline Sample & $\mathbf{p H}$ & $\begin{array}{c}\mathbf{Z n} \\
(\mathbf{p p m})\end{array}$ & $\begin{array}{c}\mathbf{C u} \\
(\mathbf{p p m})\end{array}$ & $\begin{array}{c}\mathbf{M n} \\
(\mathbf{p p m})\end{array}$ & $\begin{array}{c}\mathbf{F e} \\
(\mathbf{p p m})\end{array}$ \\
\hline $\mathrm{A}$ & 8.10 & 1.005 & .865 & 13.90 & 11.75 \\
\hline
\end{tabular}

\section{REFERENCES}

[1] Rajkumar Nagarajan, Subramani Thirumalaisamy and Elango Lakshumanan, "Impact of leachate on groundwater pollution due to non-engineered municipal solid waste landfill sites of erode city, Tamil Nadu, India",9:35,1,December 2012

[2] Jatin singla, Rita mahajan and Deepak bagai , "analysis of concentration of heavy metals in Soil", IJSRSET, 5,2017.

[3] Rajkumar joshi and Sirajuddin ahmed, "Status and challenges of municipal solid waste management in India:A review", 2:1139434,7,2016.

[4] A. santhoshkumar, R. Muthu dinesh kumar, D.babu, Vinoth thangarasu and R. Anand, "Effective utilization of High-grade energy through thermochemical conversion of different waste",https://doi.org/10.1007/978-981-13-3281-4_11.

[5] Jatin singla, Rita mahajan and Deepak bagai, "Analysis of concentration of heavy metals in soil”, $5,194,2017$. 